\title{
How might residential PV change the energy demand curve in Poland
}

\author{
Jakub Jurasz ${ }^{1}$,a, Magdalena Krzywda ${ }^{1}$ and Jerzy Mikulik ${ }^{1}$ \\ ${ }^{1}$ AGH University, Department of Management Engineering, 30-067, Gramatyka St., Cracow, Poland
}

\begin{abstract}
Photovoltaics (PV) in terms of installed capacity play a minor role in the portfolio of renewable energy sources (RES) in Poland. However current market tendencies indicate that residential PV installations are gaining on popularity and may in future significantly contribute to covering national energy demand. This study investigates the potential impact of numerous residential PV installations on the shape and statistical properties of the polish energy demand curve. Analysis employed statistical data on mean household energy consumption in different districts, typical energy demand patterns and hourly values of irradiation for the year 2012. Obtained results indicate that there is a possibility to integrate in total as much as 300000 residential PV installations $(0.9 \mathrm{GW})$ from which generated energy will be utilized by households within given district. Further analysis has shown that to some extent increasing number of residential PV decreases the value of energy demand coefficient of variation.
\end{abstract}

\section{Introduction}

Great diversity of factors shapes the volume of energy demand and its patterns. But it is the advent of RES and particularly variable renewable energy (VRE) that lead to a situation when not only demand is varying in time and space but also energy supply. Therefore the integration of non-dispatchable power sources such as $\mathrm{PV}$ and wind turbines creates as serious challenge for power grid operators. Jones [1] highlights several possible ways to effectively overcome major difficulties associated with VRE. One of them is to use energy sources which complement each other in time and space domain this is for example the case of wind and solar energy [2, 3].

It is clear that wind and solar energy exhibit diurnal and annual patterns of their availability. Solar ones can be calculated based on clear-sky models [4], but they are usually disturbed by clouds, fog and particulate matter. This makes forecasting energy yield from PV installations an arduous task but according to literature not an impossible one [5]. The results presented in [6] indicate that PV energy generation patterns positively correlate with polish power load curve during the first hours of each day - just after sunrise. This indicates that this power source may beneficially contribute to covering energy demand.

The aim of this research is investigate the impact of rather small $\left(3 \mathrm{~kW}_{\text {peak }}\right)$ residential PV installations on energy demand curve in Poland. The main task was to evaluate the changes in energy demand statistical parameters and the occurrence of energy surpluses for scenarios considering different number of households owning PV installation.

\section{Method and data}

Poland is divided into 16 voivodeships, these are further divided into districts (380 in total) and these in turn are divided into communes (about 2500). Central Statistical Office CSO (http://stat.gov.pl/) provides data on mean annual household energy consumption on a district level. For the purpose of this study only households in the countryside were selected, therefore districts with city rights were excluded from further investigation. This leaves a total of 314 districts for further analysis. Figure 1 shows location of those districts - points indicate the centre of their surface.

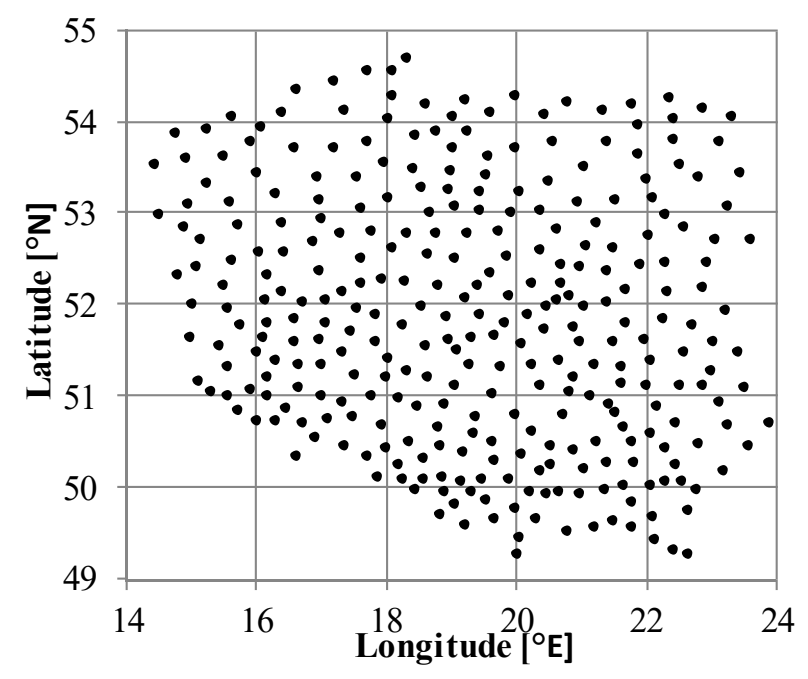

Figure 1. Sites for which irradiation time series where collected, and simultaneously districts surface centres.

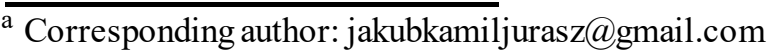


Energy consumption in households comes from various appliances, electronics, lighting, water heating, air conditioning and space heating. Demand patterns depend on number of inhabitants, life style, external temperature and time of the year. In Poland, several studies were conducted in order to estimate typical household energy demand patterns [7, 8,9]. This research bases on their results, by using those patterns. In case of each district the typical daily energy demand pattern (see for example Figure 2) has been recalculated based on annual demand pattern (see Figure 3) and specific for each district sum of energy consumed per year (see Figure 4).

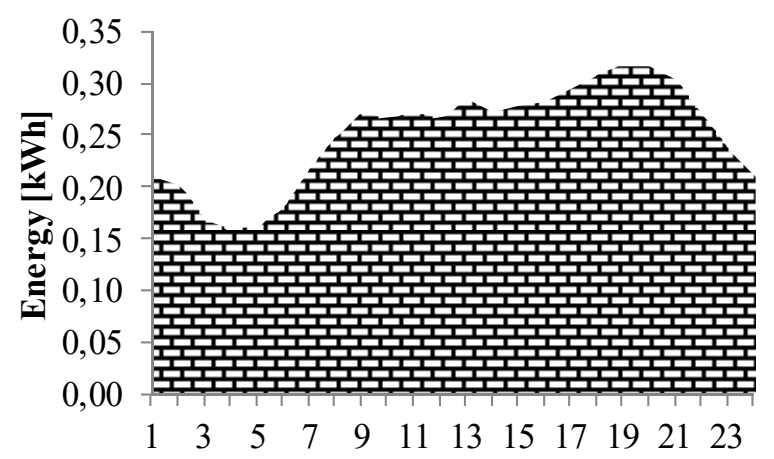

Figure 2. Mean hourly energy demand for a household in Bolesławicki district in June.

Additionally for each district data on the number of households were collected - this information was then used to estimate the number of possible PV systems which can be installed in a given district. In case of one district (Tczewski) which exhibited abnormally high energy consumption (over 8 MWh/annum per household) data from the year 2011 was used, in all remaining cases from the year 2012.

In order to calculate the energy yield from PV installations, hourly values of irradiation for the year 2012 were obtained from Solar Radiation Data SoDa (http://www.soda-pro.com/), which has both good spatial and temporal resolution. In total 314 irradiation time series for different points (which distribution is shown in Figure 1) were gathered. Energy yield from PV installation in all cases has been calculated based on formula (1):

$$
E=\frac{G P^{P V}}{S T C} \eta^{P V}
$$

where: $\mathrm{E}$ - energy yield $[\mathrm{kWh}], \mathrm{G}$ - global irradiation $\left[\mathrm{kWh}^{*} \mathrm{~m}^{-}\right.$ 2], $P^{P V}$ - nominal power of PV installation $[\mathrm{kW}] \eta^{P V}$ - overall efficiency [\%],STC - standard testing conditions irradiance $\left[\mathrm{kW}^{*}\right.$ $\left.\mathrm{m}^{-2}\right]$.

The performance ratio here denoted as overall efficiency has been assumed to be $80 \%$ and the nominal power to be $3 \mathrm{~kW}$.

Each district is characterised by mean annual energy consumption (see Figure 4), number of households and its irradiation time series. Investigated districts have in total over 4 million single-family households and their mean annual energy consumption amounts to $2.35 \mathrm{MWh}$. Energy derived from PV installations is assumed to be utilized on-site, within given district. If energy generation exceeds total household/district demand, then this excess energy is perceived as a surplus.

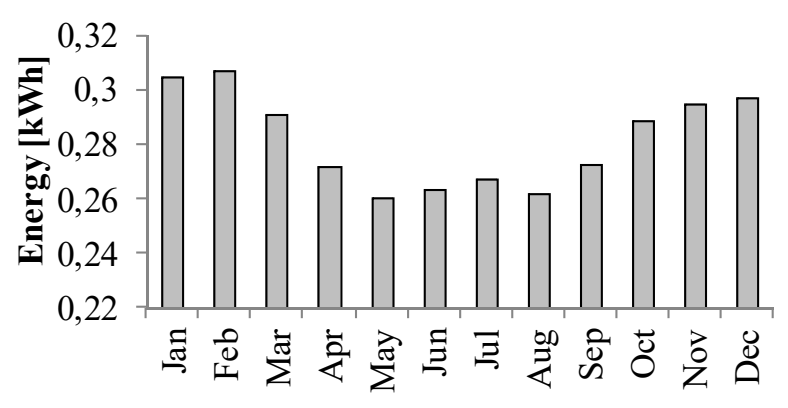

Figure 3. Mean hourly energy demand in Bolesławicki district.

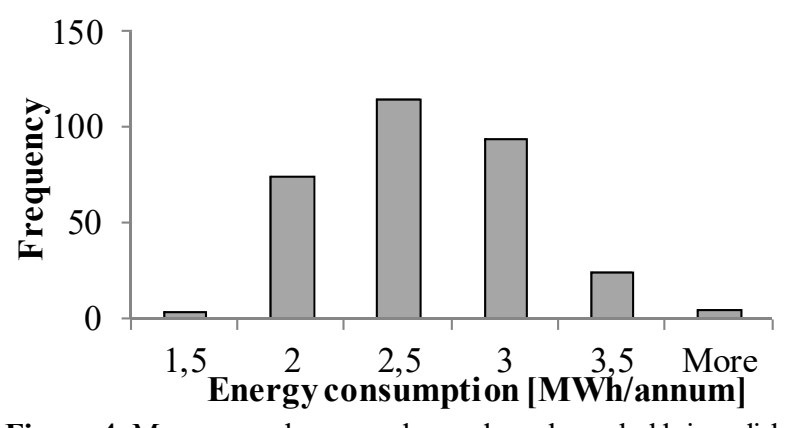

Figure 4. Mean annual energy demand per household in polish districts over the year 2012 .

From the perspective of the method proposed in this study it is also important to note that supporting development of small and distributed PV installations entails a number of benefits. According to [10] distributed generation leads to a decreased transmission losses, improves power quality and system reliability. Additionally spatial distribution of PV installation enables reduction in energy output fluctuations $[11,12]$. Therefore on may expect that on a national or a district level an ensemble of small PV installations will generate much smoother power output than one single PV farm.

\section{Results and discussion}

Based on formula (1) and collected irradiation time series the average energy yield per $\mathrm{kW}$ of installed PV capacity was $0.952 \mathrm{MWh}$. The maximal energy output was 1.01 $\mathrm{MWh} / \mathrm{kW}$ whereas the minimal was $0.877 \mathrm{MWh} / \mathrm{kW}$. According to the CSO considered households have consumed almost 11.4 TWh of electrical energy, and this was $7 \%$ of the total electrical energy used in Poland over the year 2012.

As previously mentioned it is a known phenomenon that solar irradiation values vary and exhibit both annual and diurnal patterns. The same can be observed in case of household's energy demand, however those exhibit also one more pattern, namely a weekly one. Solar energy in an adequate form is not available for PV systems overnight, therefore as a rule it is not possible to cover whole energy demand. Although this may be achieved by coupling PV with batteries and another complementary energy source, as it was for example presented for a polish household in [13]. 
Summative analysis was conducted for aggregated hourly values of energy yield from PV and households energy demand. Over the whole study, energy demand from households remained constant.

\subsection{Impact on households demand}

First of all, results on the potential impact of residential PV on households energy demand is presented. As stated earlier different levels of households owning a PV installation were investigated. Figure 5 illustrates how they might change residential energy demand in July. Due to the diurnal patterns of solar energy, this is usually not available during late afternoon. Unfortunately late afternoon and evening is the period when usually greatest energy demand is observed. In those hours energy generated from PV installations would have much greater value. Please note how residential PV systems reduce energy demand in July (Figure 5) and how they eliminate the midday demand peak. Exceeding number of $40 \%$ households having PV systemleads on average to situation when some part of energy generated cannot be used by households and must be transferred via power grid to other consumers.
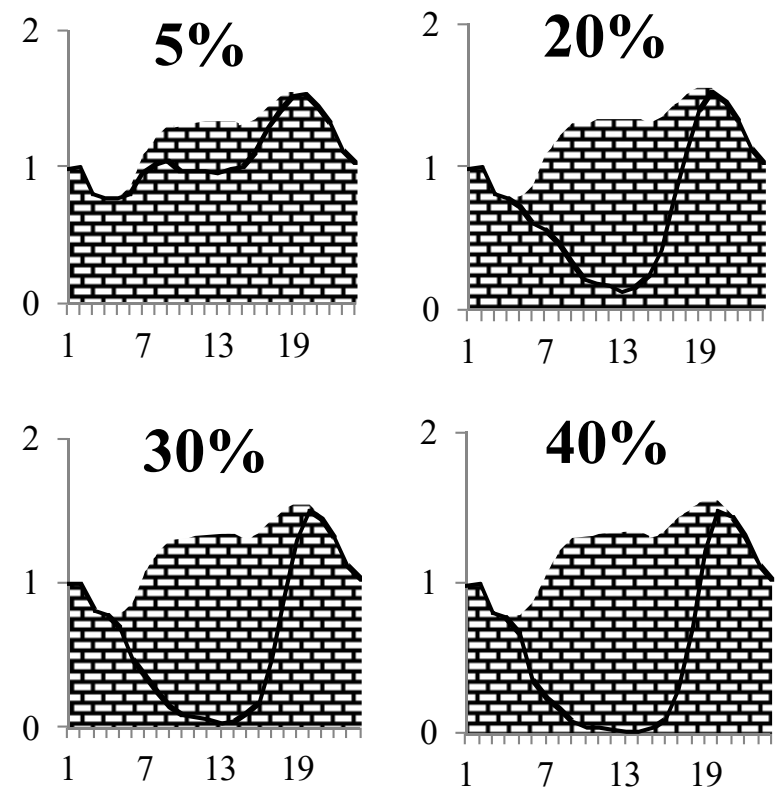

Figure 5. Average residential PV impact on aggregated households load in July. Key: OX axis - hour of the day, OY axis - energy demand in GWh, brick pattern - normal load, continuous line - load reduced by residential PV generation. Percentages indicate households with $3 \mathrm{kWp} \mathrm{PV}$ installation.

In general, over individual months PV installations have different capability of reducing average hourly energy demand. Those demand and generation patterns were investigated considering $30 \%$ households owning PV system. This translates into almost 1.47 million PV installations with nominal capacity of $4.3 \mathrm{GW}$. Analysis based on the mean hourly values indicates that such number of PV systems enables reduction in maximal hourly energy demand from April to August by accordingly: $50 ; 23 ; 85 ; 68$ and $19 \mathrm{MWh}$.
In this $30 \%$ scenario the mean hourly values of energy demand over December 2012 were reduced by $7 \%$ and as much as $50 \%$ in May. Detailed values of this reduction are presented in Figure 6. This observation is important mainly from one reason; current tendencies of load curve in Poland [14] indicate that the ratio of energy demand in winter to that in summer is decreasing. In other words, increasing demand in summer may to some extent be covered from residential and commercial PV installations.

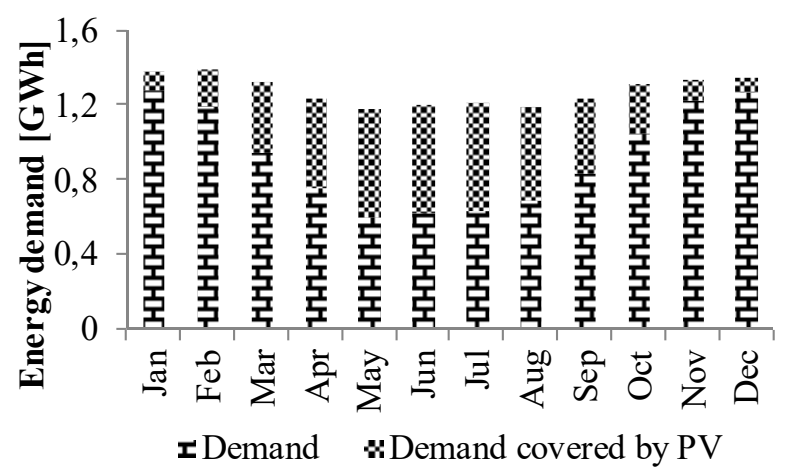

Figure 6. PV systems impact on mean hourly demand in individual months.

\subsection{National energy demand curve change}

As previously mentioned households located on rural areas constitute to roughly $7 \%$ of total energy demand in Poland. However considering various numbers of residential PV installations the impact of national energy demand curve becomes visible. Dotted line in Figure 7 represents values of energy demand coefficient of variation (CV) for each month. The $\mathrm{CV}$ values have been calculated as a ratio of the sample standard deviation to its mean. According to the data from the year 2012 the highest value of CV (exceeding 20\%) can be observed in December, over remaining months $\mathrm{CV}$ ranges from $13.5 \%$ to $15.8 \%$.

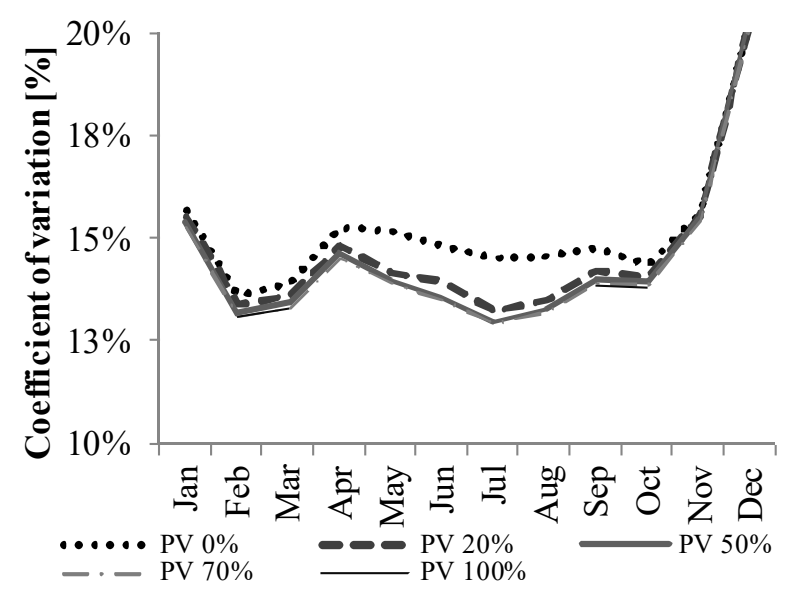

Figure 7. National power load mean monthly CV considering different share of residential PV, energy surpluses are discarded.

The CV values presented in Figure 7 were calculated based on an assumption that occurring energy surpluses do not have impact on the national energy balance. This shows that equipping even all households with PV 
systems will reduce the $\mathrm{CV}$ value of energy demand curve. In short, variable energy source used to cover household's energy demand does not introduce additional disturbance to the energy market. However discarding energy surpluses is not correct from scientific and economic point of view. Figure 8 illustrates how changes CV when energy surpluses from $\mathrm{PV}$ installations are reducing national energy demand. Now it is clear that introducing almost 4.8 million of $3 \mathrm{~kW} \mathrm{PV}$ installations (unbroken line 100\%) would cause a significant increase in energy demand curve variability. From April to June CV values exceed 20\%, and in case of almost all months (with exception to December - February) CV are greater than in baseline scenario (PV 0\%). Interestingly in case of $20 \%$ and $50 \%$ scenarios the impact on national energy demand is positive. See Figure 9 to compare those values from scenarios presented in Figure 7 and 8.

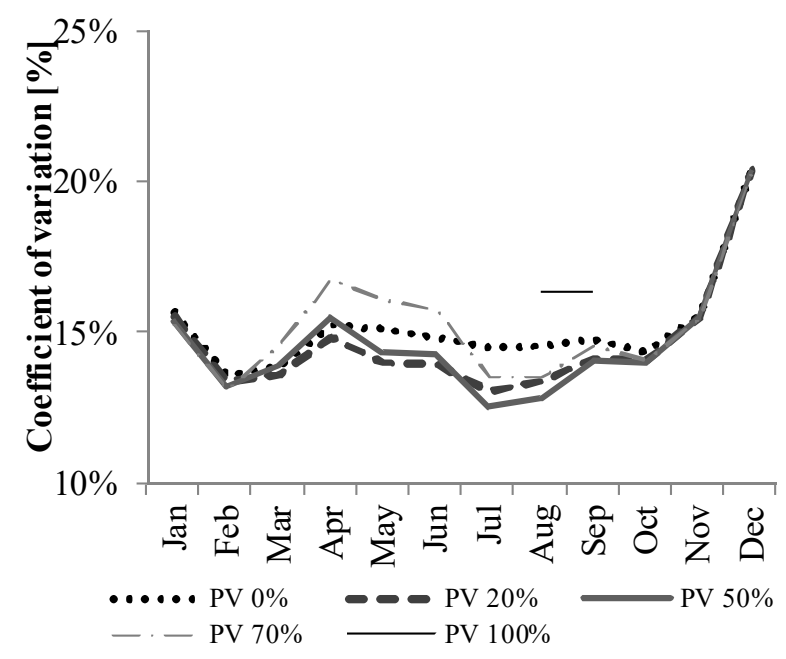

Figure 8. National power load mean monthly CV considering different share of residential PV and occurring energy surpluses

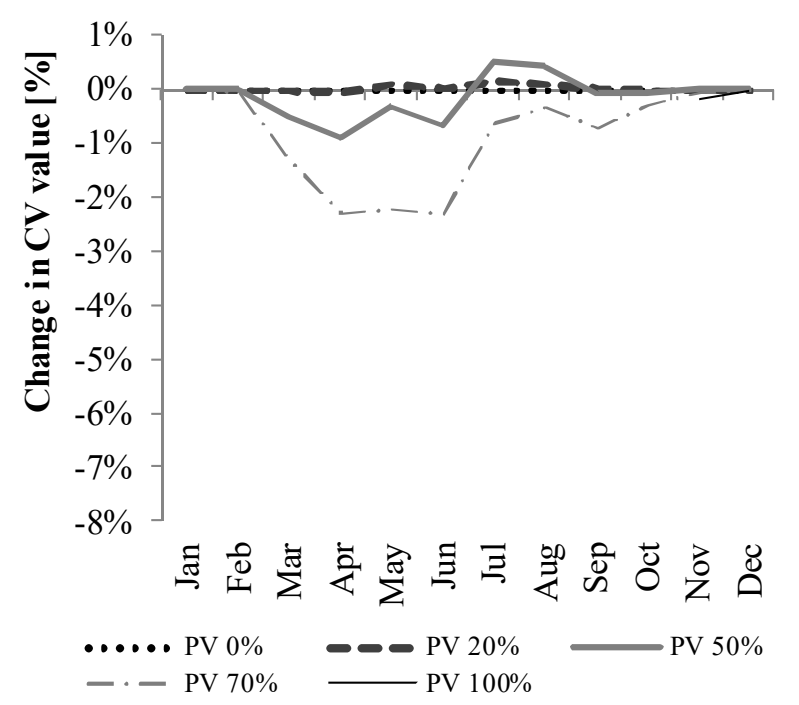

Figure 9. Differences between individual values of $\mathrm{CV}$ for two cases presented in Figures 7 and 8.

\subsection{Energy surplus from residential PV}

Energy surpluses mentioned in previous section demand more thorough analysis. An increasing number of residential PV installations undoubtedly will lead to a situation when some excess energy will be generated. This is mainly due to the energy demand patterns which make it impossible to utilize the whole energy generated from VRE. In the worst case scenario the energy may be available when it is not needed. Take for example summer, when all households' residents are running their everyday errands and energy demand is at its lowest. That is why nowadays energy storage technologies in case of VRE draw so much attention. They are perceived as a viable solution to the mismatch between energy demand and its availability.

Chart presented in Figure 10 illustrates how with increasing number of PV installations change the ratio of energy surplus to energy generated. Note that up to $10 \%$ of households owning PV system (which translates into almost 0.5 million $\mathrm{PV}$ installations of total nominal capacity equal to $1.4 \mathrm{GW}$ ) energy surpluses on a national scale does not occur. For number of households having PV installation ranging from $10 \%$ to $40 \%$ the increase of energy surplus to energy generation is much faster. This phenomenon was also observed in [6] however that study investigated the impact of PV installations on a national level, not from the perspective of household's energy demand pattern. Those results are coherent with observations made in previous section. Increasing number of PV installations, which installed capacity exceeds maximal energy demand in given area in some conditions (high irradiation) will lead to energy surpluses. Those surpluses (if not forecasted) will be perceived by power system operator as a disturbance. Additionally, according to the current market regulations so called green energy has priority before energy generated from conventional fuels - which in case of Poland is dominated by hard and brown coal [15]. This results in a situation when conventional power plants to some extent are forced to ramp up and down to adjust to the changing energy generation from VRE. This comes with additional costs and negative impact on power plant efficiency [16].

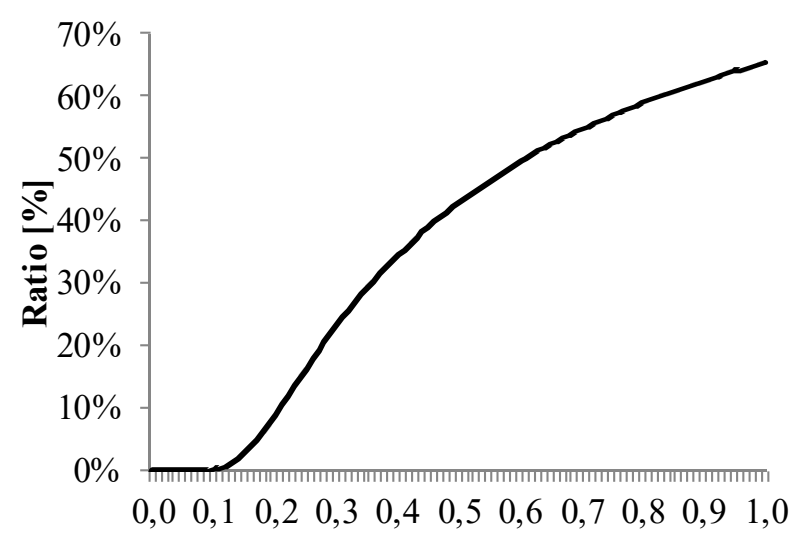

Households with residential PV $100[\%]$

Figure 10. Ratio of energy surplus to energy generation considering various number of households with PV systems.

Considering the fact that over typical year about $80 \%$ [17] of solar energy available in Poland can be used only from April to October, and minimal values on energy 
demand in households fall on this period there is no wonder that biggest energy surpluses from residential PV will occur over those months. Based on $30 \%$ scenario and 2012 irradiation values, those surpluses in May can constitute to over 50\% of energy generated (see Figure 11). From April to August over $30 \%$ of the generated energy is perceived as a surplus, in June and July it is even higher and exceeds $40 \%$. Increasing demand on air-conditioning may in future be a viable option to utilize this excessive energy [18]. It is important to note that air-conditioning is commonly used in office buildings which are rapidly developing in Poland. This may be a very important market niche for so called building integrated or building applied photovoltaics (BIPV/BAPV).

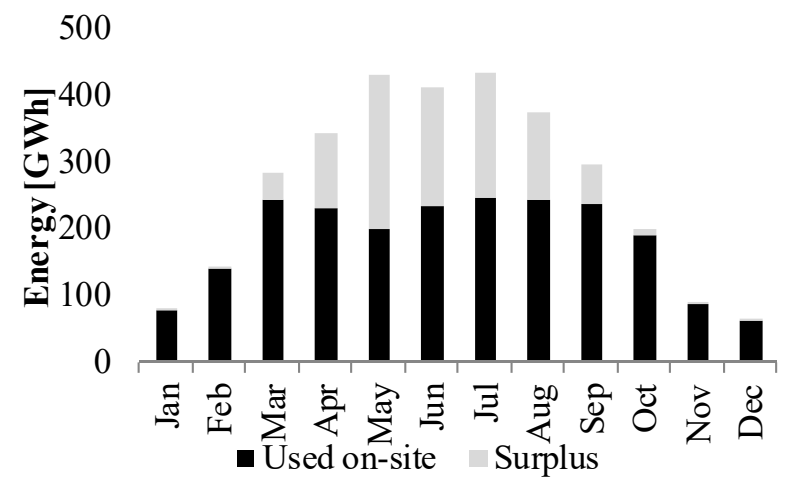

Figure 11. Energy consumed by households and energy surplus in case of 30\% households with installed PV systems.

Interesting phenomenon can be observed when analysis of energy surpluses is conducted on the district level of its generation in consumption. According to the data presented in Figure 12 almost 90\% districts have energy surpluses smaller than $5 \mathrm{GWh}$ but clearly there are some districts where those surpluses are much greater than in others.

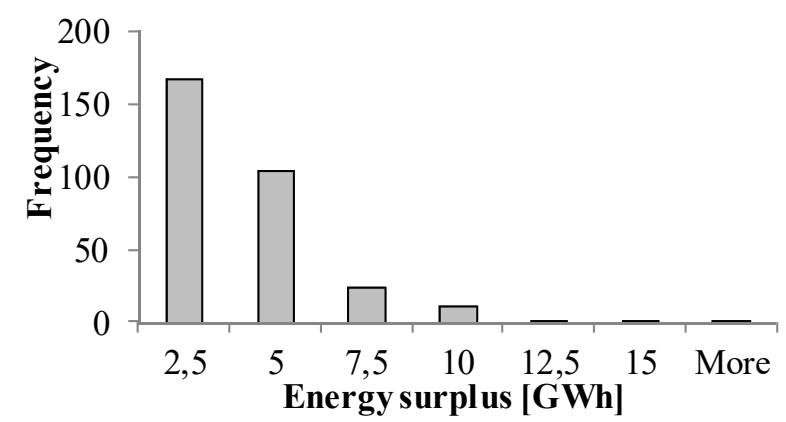

Figure 12. Histogram of annual sum of energy surpluses in different districts, for $30 \%$ PV scenario.

Scatter plots presented in Figures 13-15 show the relation between energy surpluses and three factors which may potential influence those, namely: mean energy generation, mean energy demand and the number of households. All charts were obtained for $30 \% \mathrm{PV}$ scenario. According to the presented values of the coefficient of determination $\left(\mathrm{R}^{2}\right)$ only number of households exhibits positive correlation with energy surpluses. Interestingly two outliers on Figure 14 (marked by broken line) are examples of districts with highest mean energy demand, however the occurrence of energy surpluses in those cases is clearly driven by significantly greater number of households.

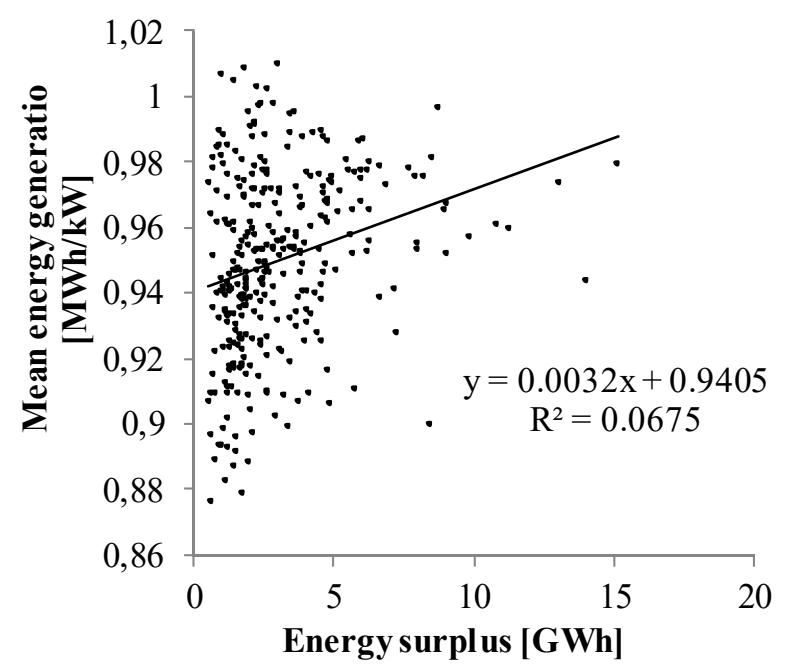

Figure 13. Relationship between mean energy generation and energy surpluses.

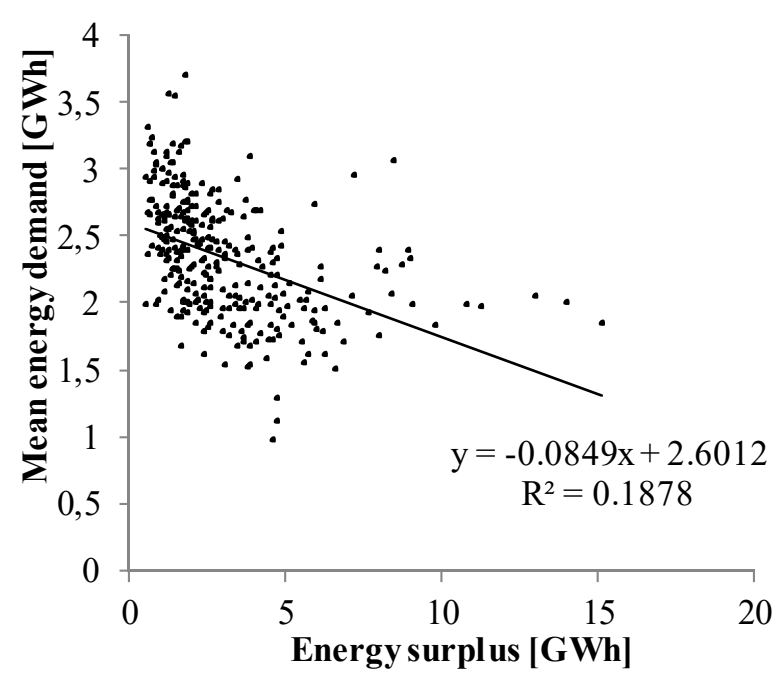

Figure 14. Relationship between mean energy demand and energy surpluses.

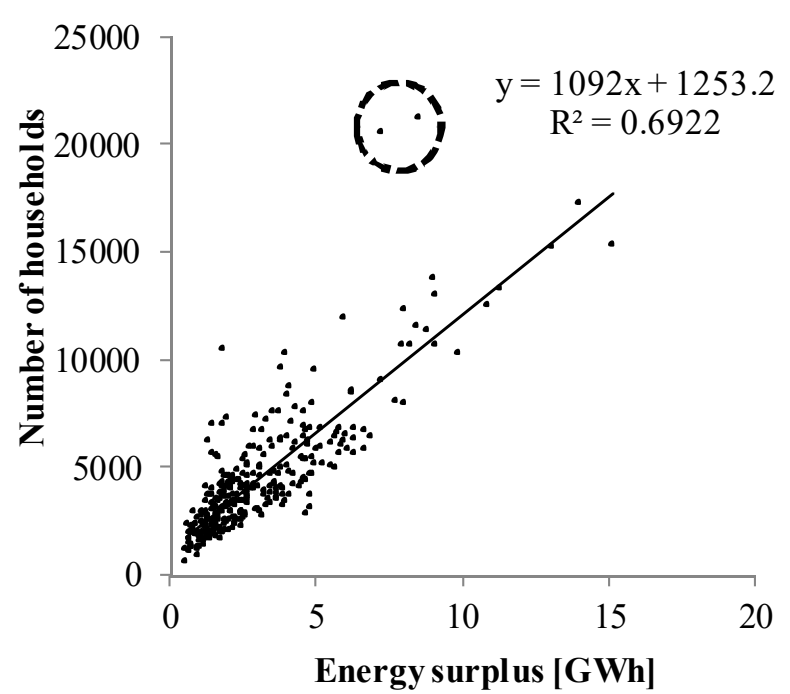

Figure 15. Relationship between number of households and energy surpluses. 


\section{Conclusions}

Conducted analysis and obtained results indicate that PV systems have huge potential to cover a significant part of households energy demand. It has been also found that daily energy generation PV patterns match well with typical energy demand in early daily hours. In case of residential energy demand, photovoltaics are capable of reducing mean hourly demand but due to the nature of solar radiation they cannot contribute to covering daily peak demand. Further analysis on the impact of PV on the energy demand curve in Poland has shown that: integrating as much as 4.3 to $5 \mathrm{GW}$ of PV may still lead to a decrease in energy demand coefficient of variation, and distributing $1.4 \mathrm{GW}$ of PV among $10 \%$ households of each district will no entail an occurrence of energy surpluses. Additionally, according to the recently conducted analysis [19] in Poland the temperature impact on energy demand in getting on importance. Meaning that not only cold days lead to a greater energy demand but also sunny and hot ones. This may result from an increasing interest in air-conditioning (AC) devices. They become irreplaceable as daily temperatures are becoming higher and higher and one has to ensure adequate working conditions in offices. What is more, the residential AC market in Poland is developing. Therefore due to the positive correlation between irradiation values, temperature and air-conditioning demand the future role of $\mathrm{PV}$ in providing extra power when $\mathrm{AC}$ is operating seems to be obvious.

\section{References}

1. L. E. Jones, Renewable energy integration: practical management of variability, uncertainty, and flexibility in power grids. Academic Press, (2014)

2. Ch. E. Hoicka, I. H. Rowlands. Ren. E. 36.1,97107 (2011).

3. J. Jurasz, A. Piasecki, Acta Energetica, 2 (2016).

4. R. E. Bird, and R. L. Hulstrom. Simplified clear sky model for direct and diffuse insolation on horizontal surfaces. No. SERI/TR-642-761. Solar Energy Research Inst., Golden, CO (USA), 1981.

5. Vaz, A. G. R., Elsinga, B., van Sark, W. G. J. H. M., \& Brito, M. C. Ren. E. 85, 631-641 (2016).

6. J. Jurasz, J. Mikulik, Investigating Theoretical PV Energy Generation Patterns with Their Relation to the Power Load Curve in Poland. International Journal of Photoenergy, vol. 2016, Article ID 3789840, 7 pages, (2016). doi:10.1155/2016/3789840

7. R. Frąckowiak, T. Gałan. Electric Load in the G12 Tariff for Consumers Assigned to the PTPiREE C-profile. Acta Energetica (2014).

8. R. Frąckowiak, T. Gałan. Przegląd Elektrotechniczny 85, 156-159 (2009).

9. R. Frąckowiak, T.Gałan. Rynek Energii 4 (2012).
10. P. P. Barker, and R. W. De Mello. Determining the impact of distributed generation on power systems. I. Radial distribution systems. Power Engineering Society Summer Meeting, (2000). IEEE. Vol. 3. IEEE, 2000.

11. E., Boudewijn, and W. van Sark.. Prog. in Photov:: Res. and App. 23.10, 1390-1397 (2015).

12. J. Jurasz, J. Mikulik. Rynek Instalacyjny, 11,3537 (2015).

13. J. Jurasz, J. Mikulik. Architecture, Civil Engineering, Environment, 4,:5-10 (2015).

14. J. Jurasz, J. Mikulik, Przegląd Elektrotechniczy 92, 152-154 (2016):.

15. H. L. Gabryś, Energetyka 03-04 (2012).

16. K. Van den Bergh K, and E. Delarue. Energy Conversion and Management 97, 70-77 (2015):.

17. Wacławek M, Rodziewicz T. Ogniwa słoneczne. Wplyw środowiska naturalnego na ich prace. (Solar cells. Influence of environment on their performance). II edition. Warszawa: WNT; (2015).

18. Davis, L. W., \& Gertler, P. J. Proc. of the Nat. Acad. of Sci., 112(19), 5962-5967 (2015)

19. J. Jurasz, J. Mikulik and A. Piasecki. Przegląd Elektrotechniczny 97 (2016): In Press Corrected Proof 